\title{
CONSTRUCTOS QUE HAN INCIDIDO EN EL RENDIMIENTO ACADÉMICO EN LA CARRERA DE INGENIERÍA AGROINDUSTRIAL EN LA SEDE REGIONAL UNI NORTE
}

\author{
CONSTRUCTS THAT HAVE INCIDED IN ACADEMIC PERFORMANCE IN THE \\ AGROINDUSTRIAL ENGINEERING CAREER AT THE UNI NORTH REGIONAL
}

\author{
Luis María Dicovskiy Riobóo ${ }^{1}$
}

Manuel Enrique Pedroza ${ }^{2}$

(Recibido/received: 11-Febrero-2020; aceptado/accepted: 28-Abril-2020)

RESUMEN: Se estudiaron los factores que influyeron en la calidad del Rendimiento Académico de los estudiantes de la carrera de Ingeniería Agroindustrial en la UNI Norte, Nicaragua. La investigación tuvo un Enfoque Mixto, se integraron métodos de investigación cuantitativos y cualitativos. Estos incluyeron: análisis estadístico correlacional, univariado y multivariado, modelación estadística avanzada, entrevistas, grupos focales, análisis de contenido y encuestas actitudinales. Los datos cuantitativos se recolectaron de las bases de datos académicas y de encuestas en línea. Se implementó Minería de datos. La información cualitativa fue aportada por estudiantes de los años superiores y docentes de la carrera. Explicando el rendimiento académico se identificaron tres constructos: Género, Motivación y Metacognición. Se recomendó implementar estrategias de aprendizaje en los estudiantes, ofrecer capacitación continua en los docentes, que se modifique el currículo y los reglamentos académicos, definir una política de género en el ingreso y monitorear el rendimiento académico mediante minería de datos con las bases de datos disponibles.

PALABRAS CLAVE: investigación académica universitaria, motivación, metacognición, género, ingeniería.

ABSTRACT: Factors that influenced the quality of academic performance in students of Agroindustrial Engineering, at UNI Norte, Nicaragua, were studied. The research had a mixed approach, quantitative and qualitative research methods were integrated. These included: correlational, univariate and multivariate statistical analysis, advanced statistical modeling, interviews, focus groups, content analysis and attitudinal surveys. Quantitative data were collected from academic databases and online surveys. Data mining was implemented. Qualitative information was provided by students of the higher years and teachers of the career. Explaining the academic performance, three constructs were identified: Gender, Motivation and

${ }^{1}$ UNI-Sede Regional Norte, Nicaragua. luis.dicovskiy@norte.uni.edu.ni

2 Universidad Nacional Autónoma de Nicaragua, Managua 
Metacognition. It was recommended to implement student learning strategies, offer continuous teacher training, modify the curriculum and academic regulations, define a gender policy on admission and monitor academic performance through data mining with available databases.

KEYWORDS: university academic research, motivation, metacognition, gender, engineering.

\section{INTRODUCCIÓN}

La calidad del rendimiento académico en la enseñanza de las ingenierías no solo impacta en el futuro estudiante y en su familia, sino en la sociedad en general. Cuando ocurre deserción de estudiantes, no solo se pierde la oportunidad de tener ingenieros formados localmente y con capacidad de incidir en el desarrollo tecnológico de la región, sino también se generan altas pérdidas económicas al país. La formación de ingenieros es de las más caras entre las carreras universitarias.

A partir de datos de los años 2011- 2013, se determinó que había habido una tasa de graduación baja en la carrera de Ingeniería Agroindustrial de la Universidad de Ingeniería sede regional Norte, UNI Norte, esta información indicó la ocurrencia de problemas serios de deserción o retrasos en graduar a los nuevos profesionales. Dado que, faltaba investigación sobre las causas que habían incidido en la Tasa de Graduación histórico de la carrera y por ende en la calidad de los graduandos, se planteó realizar una investigación sobre el rendimiento académico en la carrera de Ingeniería Agroindustrial.

De la información académica histórica que se disponía y de la experiencia de los estudiantes de los años superiores y sus docentes, se generó una oportunidad para integrar métodos cuantitativos y cualitativos, en una investigación sobre las causas que han favorecido el éxito o fracaso de los estudiantes. Esto permitió proponer recomendaciones educativas y aportar una nueva metodología para generar nuevos conocimientos. Los hallazgos relevantes demostrados en esta investigación, podrían ayudar a mejorar la eficiencia de graduación y por ende la calidad académica de los estudiantes que cursan ingeniería, de manera particular en la UNI Norte y de forma extensiva a todas las universidades que impartan ingenierías en Nicaragua.

\section{METODOLOGÍA}

La presente investigación, hizo uso y análisis de datos cuantitativos y cualitativos, así como la integración y discusión holística y sistémica de diversos métodos y técnicas cuali-cuantitativas de investigación, esta se realizó mediante la aplicación del Enfoque Mixto de Investigación (Hernández et al., 2014). La investigación se identificó con el Paradigma Socio-Crítico.

De acuerdo al método de investigación el presente estudio fue observacional y según el nivel inicial de profundidad del conocimiento fue descriptivo (Piura López, 2006). De acuerdo a la clasificación de Hernández, Fernández y Baptista (2014), el tipo de estudio fue correlacional. De acuerdo, al tiempo de ocurrencia de los hechos y registro de la información, el estudio fue

El Higo Revista Científica / Volumen 10. No. 01, pp. 38-52 / Junio 2020 


\section{Luís M. Dicovskiy R.; Manuel E. Pedroza}

retrospectivo, por el período y por la secuencia del estudio fue transversal y según el análisis y alcance de los resultados el estudio fue analítico y predictivo (Canales, Alvarado y Pineda, 1994).

De acuerdo a sus características particulares, para el análisis de causalidad y predicción en esta investigación, los sujetos de estudio. Los estudiantes no fueron asignados al azar a los grupos de manera predefinida, sino que dichos grupos y sus repeticiones ya estaban prefijados antes del experimento, estos ya están formados de forma independiente. Por tanto, los datos se organizaron de acuerdo a la lógica de un Diseño Cuasi experimental (Hernández et al., 2014).

La investigación se realizó en el departamento de Estelí, con base en la Universidad Nacional de Ingeniería, UNI, Sede Regional Norte, situada en la salida a la Tunosa, antigua "Hacienda El Higo "en Estelí. El período a estudiar fue el 2005-2018.

La población objeto de estudio en el análisis estadístico fue definida por todos los registros de la base de datos histórica, de los registros académicos de la carrera de Ingeniería Agroindustrial UNI Norte, durante el período de 2005-2015. El tamaño de la muestra representativa en el presente estudio, se corresponde con el criterio de censo, es decir incluye todos los registros académicos disponibles para esta población. El total de registros académicos disponibles en este estudio fue de 556 estudiantes. La unidad de observación fueron los datos de los estudiantes o ellos mismos.

Para las encuestas de opinión sobre la carrera, la población fueron los estudiantes presentes en tercero y cuarto año en el año 2017. Las encuestas sobre Metacognición y Motivación se hicieron en el año 2018. En la encuesta de valoración docente, la población fue todos los estudiantes de agroindustria en cuatro semestres 2016-2017. Con los docentes de la carrera se hicieron de entrevistas y grupos focales con los estudiantes de cuarto y quinto año, en ambos casos se usó el concepto de Muestra Teórica, hasta la saturación de contenidos, estas se hicieron en los años 2017 y 2018.

La ética de la investigación, un aspecto muy importante para el paradigma cualitativo, se abordó desde diferentes aspectos éticos y conceptos asociados. Los aspectos éticos tomados en cuenta fueron: el tema, los sujetos, el contexto, el tiempo y el fenómeno. Estos elementos éticos se cruzaron con los conceptos: fidelidad de la fuente, el no involucramiento y el no establecer diferencias y derechos. 


\section{RESULTADOS Y DISCUSIÓN}

\section{Factores que han incidido en el Rendimiento Académico}

Los objetivos del plan de estudio de la carrera de Ingeniería Agroindustrial, son el eje articulador del plan de estudio y estos demostraron ser pertinentes cuando se los contrastó con los Objetivos de Desarrollo que propone el PNUD para el nuevo milenio.

Se observó cuantitativamente que las mujeres tuvieron un $11 \%$ de mayor porcentaje de aprobación de asignaturas en aula, $X^{2}=370, p<0.0001$, y mejor promedio final de notas de más de 3 puntos, $t=18.9, p<0.0001$. Las asignaturas de Matemáticas tuvieron de promedio 10 puntos menos que las asignaturas de tipo social, $\mathrm{t}=-20.3, p<0.0001$. Comportamiento de este tipo se ha reportado en varios estudios sobre género y rendimiento académico universitario, a continuación, se citan ejemplos de esto. Casos de mejor comportamiento académico por parte de las mujeres fueron observados por Giovagnoli (2002), que reportó que un varón tenía una 1.36 veces más posibilidad de abandono en la universidad. Los estudiantes varones tuvieron una probabilidad de 0.394 veces menos de tener un buen rendimiento académico en primer año de su carrera, según Barahona (2014). García (2014), al recopilar trabajos científicos sobre factores que han incidido en el rendimiento académicos de los jóvenes universitarios argentino, encontró que en general la bibliografía reportaba un mejor desempeño de las mujeres.

Los datos académicos mostraron que el primer año de la carrera es el que tiene mayor deserción en aula con un $16 \%$, figura 1 ; que el municipio de origen de los estudiantes influye en las notas del primer semestre de la carrera, no así el tipo de colegio Secundario, privado o público, $t=-2.6$, $p=0.0084$. A continuación se citan ejemplos de referencias donde se hace mención que la mayor cantidad de la deserción universitaria, se sitúa en el primer año de la carrera: Abarca Rodríguez y Sánchez Vindas (2005), Tejedor Tejedor y García Valcárcel (2007), C. J. Díaz (2009), Salazar Francis y García Solórzano (2011), Olave Arias et al. (2013), Henríquez y Escobar (2016), A. Canales y De los Ríos (2018). Merlino y Ayllon (2015), dicen que el primer año de la universidad está fuertemente correlacionado con la mayoría de las variables que muestran la historia preuniversitaria del estudiante. Vergara Morales et al (2017), en Chile, encontraron vinculación entre la deserción temprana y la región de procedencia del estudiante. Sin embargo Barahona (2014), en la tercera región en Chile halló que la procedencia del tipo de establecimiento: particular subvencionado o público, resultó no ser estadísticamente significativo en la notas de primer año en la Universidad de Atacama, pero aclara que en esta región no hay colegios privados de élite, cómo en la capital, algo así ocurre en Estelí. 


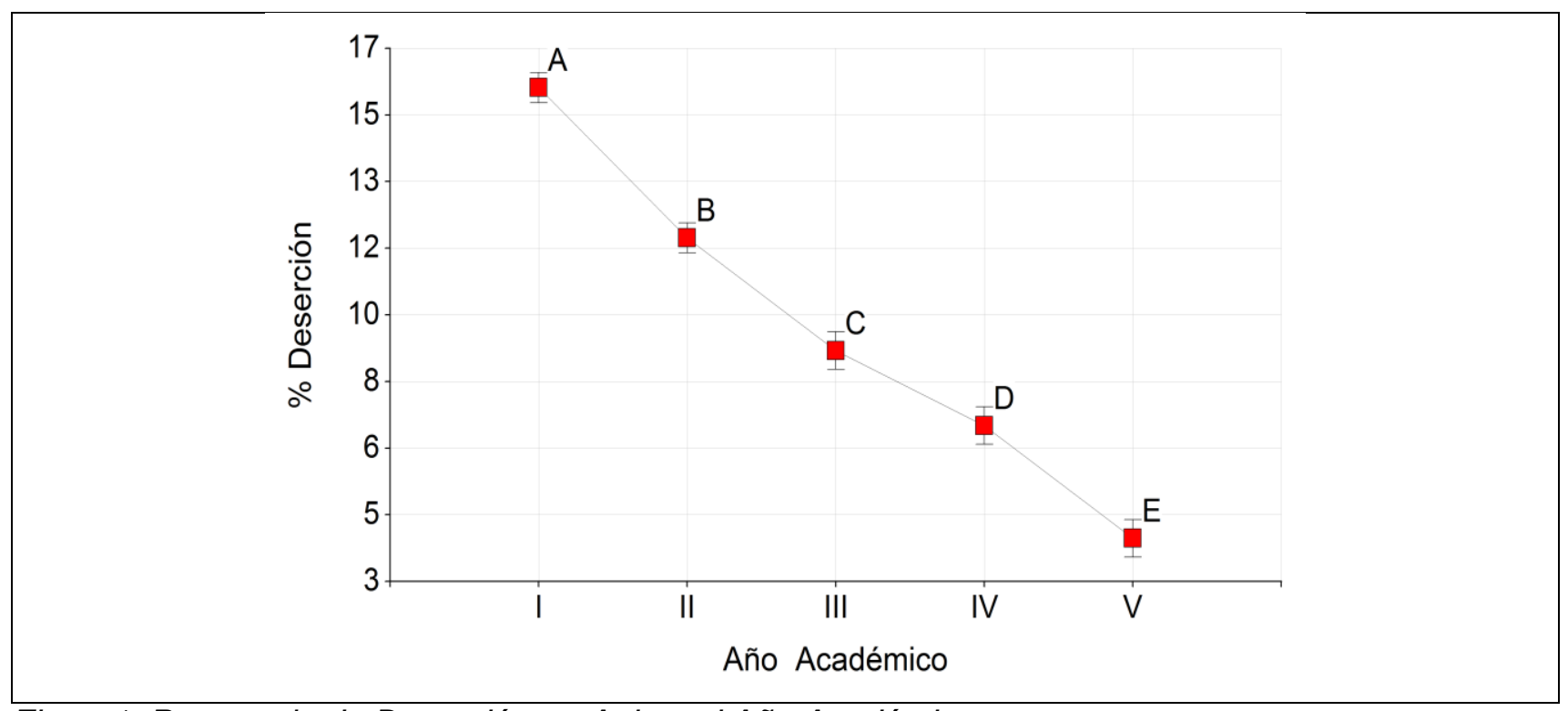

Figura1. Porcentaje de Deserción en Aula y el Año Académico.

\section{Asociaciones y Causalidad de Factores que inciden en el Rendimiento Académico}

Los datos académicos, históricos, con una base numérica en la nota final de las asignaturas, expresaron hechos objetivos, los cuales se demostró que suelen coincidir con los resultados de investigaciones académicas universitarias previas, aún en diferentes contextos. En general no se encontraron contradicciones entre lo observado en los datos estadísticos, la información cualitativa y la teoría de referencia. Se verificó la dependencia altamente significativa, valor $p<$ 0.0001, de los factores: Género y Año Académico con los factores: Notas en Categorías y Deserción en Aula.

Se demostró mediante la aplicación de Modelos Lineales Generales y Mixtos, en relación a sus factores, una mejora de la calidad estadística de los análisis. Se encontró que, para una mejor interpretación cuantitativa del rendimiento académico, la variable numérica Nota Final que está disponible en todas las bases de datos académicas, se fraccione en tres nuevas variables: "\% Deserción en aula $=$ nota final $=0$ "; "\% de Reprobados $=\%$ de: $0<$ Nota Final $60<$ " y "Nota Final de los Aprobados $=60 \leq$ Nota Final $\leq 100$."

Las dos primeras variables, "\% Deserción en aula" y "\% de Reprobados" son dicotómicas y facilitan dos informaciones claves, que porcentaje de estudiantes abandonan su aula y que porcentaje de estudiantes aprueban o reprueban sus asignaturas. La tercera variable, que se observó presenta normalidad en su distribución, permitió realizar pruebas de hipótesis, cómo análisis de variancia en modelos mixtos, sobre las diferentes variables de agrupación que tenga la base de datos, por ejemplo, Nota y Género, Nota y Año académico, Nota y municipio de procedencia, Nota y tipo de asignaturas, Nota y tipo de colegio secundario de procedencia, etc.

El mejor modelo de análisis fue el que tuvo los Factores Aleatorios: Estudiante y Docente. Se observó diferencias significativas entre los factores de efectos fijos Año académico ( $F=5.67, p<$

El Higo Revista Científica / Volumen 10. No. 01, pp. 38-52 / Junio 2020 
$0.0001)$ y Género $(F=279.81, p<0.0001)$. Sin embargo, no se encontró interacción significativa entre ambos factores.

\section{Modelos Explicativos y Predictivos de Factores que inciden en el Rendimiento Académico: Género, Motivación, Metacognición}

Las estudiantes mujeres, desde el momento que eligen la carrera, parecen tener un mayor compromiso con sus estudios desarrollado a partir que saben que están en un medio, las ingenierías, donde son minoría y está siendo observadas por su entorno y su familia. Cuando ellas eligieron la carrera, ya sabían que entraban en un territorio no habitual a las mujeres. Una explicación de su mejor comportamiento académico podría ser que ellas tuvieron una mayor presión social familiar que sus compañeros varones, para ser exitosas. En general ellas demostraron poseer una mejor capacidad de adaptación a la universidad. El Género demostró ser un constructo integrador, no esperado, que explicó parcialmente las diferencias de rendimiento académico de hombres y mujeres en la ingeniería estudiada.

En lo referente a las asignaturas de clases, el estudiante que tiene buenas notas en un grupo de asignaturas afines, por ejemplo, las Físico Matemáticas, también fue bien en los otros grupos de asignaturas, como las de tipo Tecnológico o Sociales, Correlación. Canónica, $R=0.9, p<0.0001$. Las notas de las asignaturas de primer año se relacionan con el factor "Éxito o Fracaso" en quinto año, (Lambda de Wilks $=26.35, p<0.0001$ ), tabla 1. Las notas de las asignaturas del primer semestre se correlacionan fuertemente con las asignaturas del segundo semestre, demostrándose ésta mediante correlación Canónica, $R=0.86, p<0.0001$.

Tabla 1. Prueba de comparación de grupos de Hotelling, notas de primer año y condición con que llegan a quinto año de la carrera.

\begin{tabular}{lc}
\hline Categoría & Signif. \\
\hline Riesgo & $\mathrm{A}$ \\
Exitoso & $\mathrm{B}$ \\
Desertor & $\mathrm{C}$
\end{tabular}

Medias con una letra común no son significativamente diferentes $(p>0.05)$

El éxito o fracaso en la asignatura de Matemática II de primer año, resultó ser un buen indicador de las capacidades necesarias para terminar la carrera $(F=175.92, p<0.0001)$. Los estudiantes reconocieron que las asignaturas más complejas en primer año son las: químicas, física y las matemáticas $\left(\mathrm{T}^{2}\right.$ Friedman $\left.=12.96, p<0.0001\right)$ y que la disciplina en el estudio, los buenos profesores y la motivación son importante para un éxito académico ( $\mathrm{T}^{2}$ Friedman $=17.78, p$ $<0.0001)$.

Se generó un modelo discriminante, con las notas del primer semestre de la carrera, que predijo con un 79 \% de acierto, que estudiantes serían exitosos o no al fin de la carrera. En este modelo, la asignatura Matemática I tenía el mayor peso específico. 
Dávila Cárdenes, García-Artiles, Pérez-Sánchez, y Gómez-Déniz (2015), concluyen que "muchos estudiantes acceden a los estudios superiores sin las capacidades y actitudes necesarias para aprovechar al máximo el proceso de enseñanza-aprendizaje universitario" (p.40). Para disminuir la deserción en el primer año de la carrera Jansen y van der Meer (2012), proponen que se deben fortalecer las prácticas pedagógicas, en este año. Arco Tirado et al. (2011), sugieren la realización de programas de tutorías con los estudiantes de los años superiores.

Responsabilidad, hábitos de estudio y disciplina son conceptos que fueron muy nombrados por los estudiantes en grupos focales y que asociaron a buen rendimiento académico. Estos conceptos son parte del constructo Metacognición del aprendizaje. La Metacognición tiene que ver con "el control y la regulación de los procesos de conocimiento, y en el caso de la educación, entre otros, el proceso del aprendizaje" (Ugartetxea, 2001). Este constructo que apareció cómo muy importante en el éxito o fracaso de los estudiantes y el cual es necesario potenciar, es la Metacognición en el aprendizaje, concepto que se manifiesta en la capacidad de autonomía en el aprendizaje y en la capacidad de autoaprendizaje que los jóvenes tienen. Este constructo fue evaluada por medio de una encuesta en línea, diseñada por S. Jaramillo y Osses (2012) y que consideran 6 factores de análisis: Conocimiento, Control y Supervisión, Planificación, Experiencias, Evaluación y Estrategias, se encontró que la Metacognición mejora en los años superiores de la carrera respecto al primer ingreso (figura 2). De manera particular, el aspecto que mejoró más con la edad fueron: las emociones, sensaciones o sentimientos que acompañan a la actividad cognitiva del estudiante y que influye significativamente en el progreso hacia la meta de un mejor rendimiento académico $(\mathrm{t}=2.13, p=0.039)$.

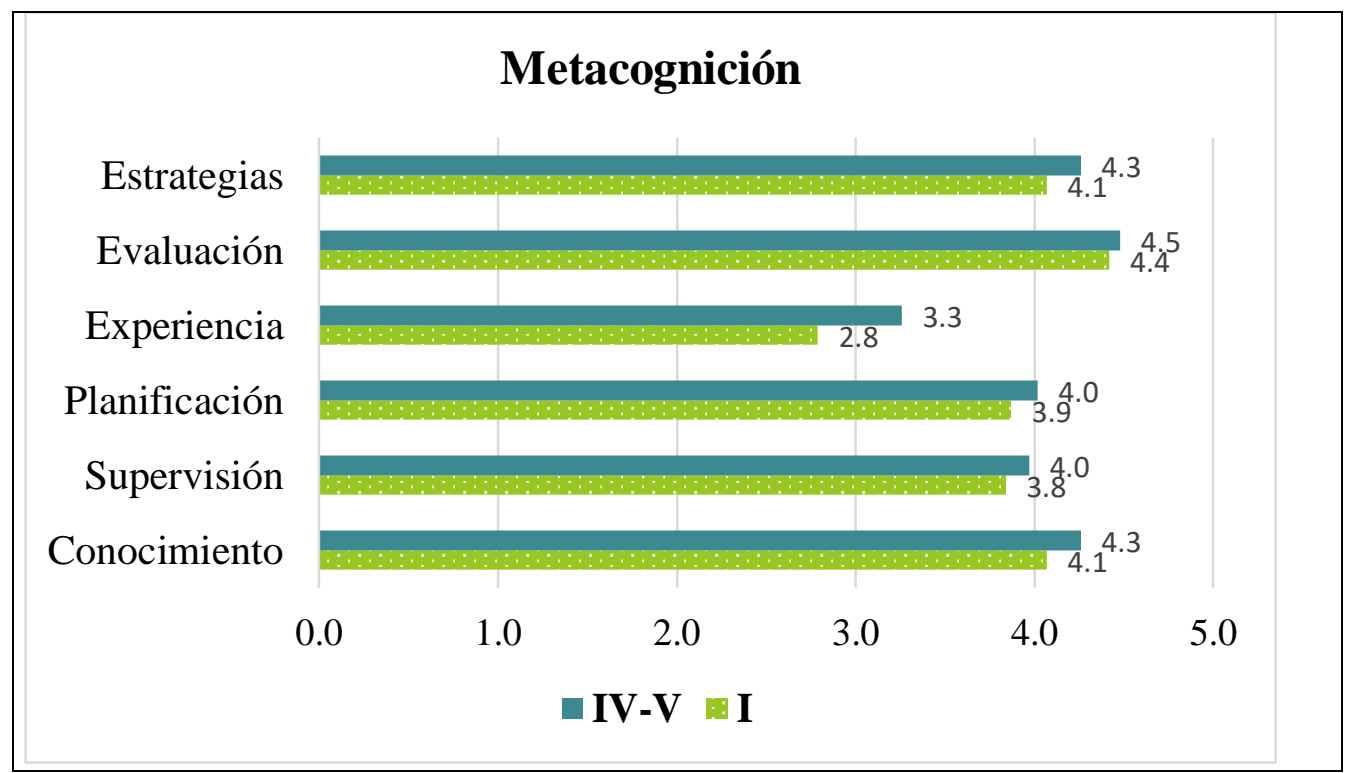

Figura 2. Metacognición por Factor y grupo: IV-V año y I año.

También se observó otro constructo, nombrado por los estudiantes y docentes como muy importante, este fue la Motivación que tienen los estudiantes a su carrera y a sus estudios. La medición de la Motivación de los estudiantes se hizo en términos de 6 componentes: Valor

El Higo Revista Científica / Volumen 10. No. 01, pp. 38-52 / Junio 2020 
Intrínseco, Valor Extrínseco, Valor de tareas, Expectativas de Creencias-Aprendizajes, Expectativas de Autoeficacia y Afectivo por Ansiedad, diseñada, por Pintrich et al. (1991), (figura 3). Esta encuesta permitió conocer que los estudiantes de los años superiores manejan mejor la ansiedad, tienen una mayor valoración en sus esfuerzos personales para lograr mejores rendimientos académicos y dan menos importancias a las evaluaciones cómo estímulo ( $\mathrm{t}=2.67$, $p=0.01)$.

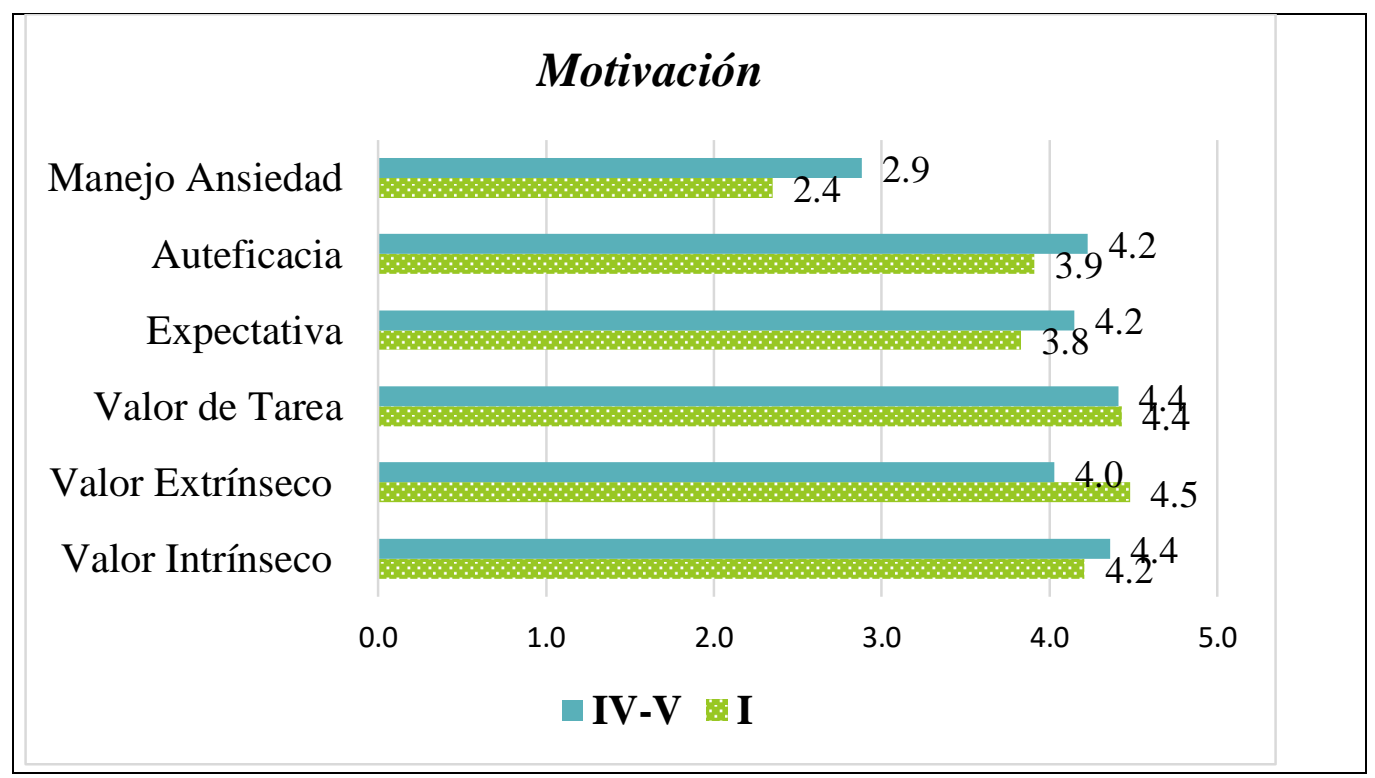

Figura 3. Motivación por componente y grupo: IV-V año y I año.

En esta investigación se observó que los estudiantes de primer año dieron más importancia de forma significativa a los estímulos de Motivación Extrínseca, grado en que el estudiante se percibe a sí mismo participando en una tarea por razones tales como calificaciones, recompensas, desempeño, evaluación por parte de otros y competencia. Romero Ariza y Pérez Ferra (2009), explican que en el caso de los estudiantes interesados únicamente por el resultado, Motivación Extrínsica, se ha detectado una mayor propensión a derrumbarse y desistir en el caso de no conseguir la meta esperada, la cual era su principal estímulo.

La motivación es un elemento clave para el aprendizaje (Alvarez Alvarez, 2005, p.109). La motivación es un predictor positivo significativo del rendimiento académico (Kohler Herrera,2013). La frustración conduce a sentimientos de inferioridad, de desamparo (Maslow, 1991). Abdala Leiva et al.(2008), vincula la falta de motivación con elección de una carrera sin información de la misma.

Las entrevistas a docentes y estudiantes, junto con las encuestas a estudiantes y la revisión teórica permiten hacer las siguientes explicaciones fundamentadas en los datos:

- El estudiante ingresa a la universidad con sus limitaciones y capacidades desarrolladas en la escolaridad previa y en su casa, como: hábitos de estudio, disciplina y valores para el estudio.

El Higo Revista Científica / Volumen 10. No. 01, pp. 38-52 / Junio 2020 
- Una fuerte Motivación y mejora de la autoestima de los estudiantes de primer año a la carrera puede ayudar a superar las debilidades previas al ingreso a la universidad.

- la Motivación actúa de diferente manera en los estudiantes de primer año en relación a los estudiantes de los años superiores. En los estudiantes de primer año tienen más importancias las recompensas externas como los resultados de las evaluaciones. Los estudiantes de los años superiores tienen más autoconfianza.

- La Metacognición mejora de forma general en los estudiantes de los años superiores y de manera particular, estos estudiantes tienen una mayor seguridad de que sus experiencias previas les permitirán un mayor progreso académico.

- Las estudiantes de los años superiores manifestaron que en el transcurso de sus estudios no sintieron discriminación por género dentro de la universidad, y se mostraron, muy empoderadas con su carrera. Sin embargo, expresaron que en las prácticas fuera de la universidad, en las empresas privadas, sintieron algún nivel de discriminación por ser mujer.

- Las mujeres, al menos de los años superiores, parecen ser más responsables, preocupadas y disciplinadas en entregar sus tareas de clases.

- Respecto a los conocimientos adquiridos en la carrera, en lo que se refiere a contenidos y habilidades específicas, en general, están bien valorados por los estudiantes.

- Los estudiantes reconocen que el éxito en la carrera está muy vinculado a tener buenos docentes, motivación a la carrera, hábitos de estudio y apoyo familiar. Por otro lado, a la universidad le solicitan para mejorar su rendimiento académico, más prácticas dentro y fuera de la universidad y más apoyo en becas estudiantiles.

- Los docentes creen que pueden incidir significativamente para cambiar el modelo docente existente, que ocasiona una mayor deserción de estudiantes en los primeros años. Ellos proponen, que se enseñe a estudiar, que se fortalezca y se amplié la utilización de alumnos monitores, tutores, y se fortalezcan las clases prácticas dentro y fuera de la universidad.

Los Constructos: Género, Motivación, Metacognición, y el entorno inciden directamente en el Rendimiento Académico. El mayor éxito académico de las mujeres se sustenta en su seguridad al elegir la carrera y un mayor control o seguimiento familiar. La motivación y la metacognición pueden ser mejorado con un temprano accionar de los docentes, acompañado con cambios en el currículo y en los reglamentos. El hecho que la universidad no actúe lo suficiente en desarrollar capacidades y valores en el primer año de la carrera, permite que exista un modelo determinista, donde las condiciones iniciales producirán los mismos resultados finales, el estudiante que no viene previamente preparado en conocimiento, hábitos de estudio, motivaciones, no se adapta bien a la forma de enseñar que se tiene en la universidad y fracasa.

La propuesta de integración de los Constructos: Género, Motivación, Metacognición, y el entorno incidiendo en el Rendimiento Académico, se presenta en la figura 4. 


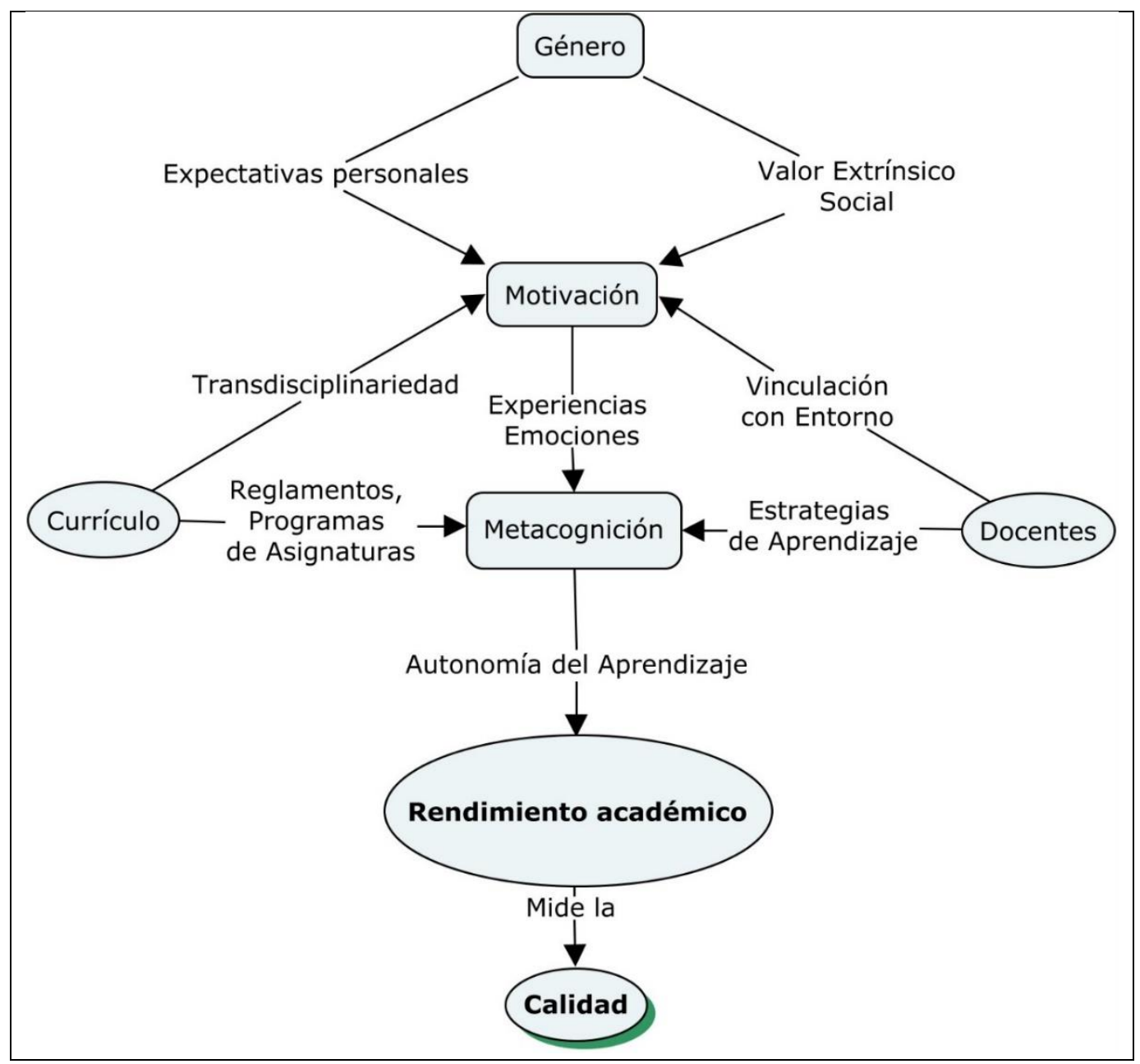

Figura 4. Relación entre Constructos, Entorno y el Rendimiento Académico.

Se parte de que, las mujeres que eligen estudiar ingenierías, tiene más expectativas de ser exitosas, están más seguras de su opción, y en general también tienen un mayor control o seguimiento familiar, lo que finalmente incide en la Motivación. Respecto al apoyo de la familia de las mujeres que estudian ingenierías, Razo Godinez (2008), encontró que la mayor parte de las estudiantes de ingenierías entrevistadas en su estudio "contaron con condiciones propicias en su familia para ingresar, sea porque las impulsaron o porque no les impusieron objeción" (p.89). Oliveros Ruiz, Cabrera Córdoba, Valdez Salas, y Schorr Wienner (2016), en su estudio sobre motivación de las mujeres para estudiar ingenierías y tecnologías, concluyen "que la familia, apoyó a las estudiantes en un gran porcentaje al decidirse elegir una carrera del área” (p.96).

Los docentes motivan a la carrera cuando vinculan su enseñanza con lo que sucede en el entorno profesional, Camarasa et al. (2014), dicen que los estudiantes no estudian si no están motivados y que las actitudes y prácticas de los profesores en el aula pueden influir en la motivación. El currículo hace el mismo papel cuando promueve la transdiciplinariedad. Esto inciden en la Metacognición y la misma en el Rendimiento Académico expresado en la nota final de las asignaturas. 


\section{CONCLUSIONES}

El análisis cuantitativo demostró que el primer año de la carrera es el que tuvo mayor deserción en aula, que las mujeres tuvieron menos deserción y mejores notas, que el municipio de origen de los estudiantes influyó en las notas del primer semestre de la carrera y se demostró correlación multivariada entre grupos de asignaturas afines. Se generó un modelo estadístico predictivo, con las notas del primer semestre de la carrera, que predijo con un $79 \%$ de acierto, que estudiantes serían exitosos o no, al fin de la carrera.

De las entrevistas y grupos focales se resume que, el éxito académico está muy asociado al apoyo familiar, la docencia debe ser práctica y motivante, la universidad debe mejorar sus servicios físicos, como los laboratorios y que el género influye en el rendimiento académico. Explicando el rendimiento académico se identificaron tres constructos integradores: Género, Motivación y Metacognición.

Se recomienda implementar estrategias de aprendizaje en los estudiantes, para esto se pueden implementar actividades, utilizando material vinculado a su carrera como: interpretación de lecturas, exposiciones utilizando diapositivas, y elaboración de resúmenes con procesadores de texto, lluvia de ideas para abordar problemas comunes, seminarios de discusión que les permita argumentar y discutir ideas, grupos nominales para conocer cómo encontrar consensos y permite la construcción de mapas conceptuales.

Los profesores deben ser actualizados de forma permanente en nuevas formas de enseñanza, a través de didácticas especiales de la educación virtual: Plataformas interactivas, video conferencias, teleconferencias, exámenes en línea, tareas y foros en línea, para actualizarse y modernizarse, por medio de diplomados, escalables a maestrías y doctorados.

A los programas de clase en la carrera de Agroindustria se debe incorporar, objetivos por unidad del tipo: conceptual, procedimental y actitudinal. Este último tipo de objetivo puede orientarse a la motivación a la carrera. Es importante que los programas de las ciencias básicas, que se dan en los primeros años de la carrera, se enseñen orientadas a desarrollar las competencias propias de la carrera. Los estudiantes deben practicar con ejemplos tomados del mundo laboral, lo que ayudará a la motivación. También se propone se transite a un modelo de evaluación que valore más los procesos de aprendizajes significativos y que permita acumular más puntos durante el desarrollo de las clases. El reglamento académico de la UNI se debe modificar en lo referente a la forma de evaluación.

La universidad debe abrir una instancia que dé seguimiento e investigue el comportamiento de los estudiantes, a partir de la información de que se dispone en las extensas bases de datos académicas existentes. Se deben utilizar el enfoque de minería datos para encontrar efectos de causalidad y correlación multivariada, así como tendencias o conductas en los estudiantes, que luego deben ser explicados con métodos de investigación cualitativa.

El Higo Revista Científica / Volumen 10. No. 01, pp. 38-52 / Junio 2020 
Se debe promover una mayor participación de mujeres en el ingreso a primer año a través de una eficaz orientación vocacional hacia las ingenierías, la cual se puede realizar en los quintos años de los colegios secundarios, que más estudiantes estén aportando a la universidad.

\section{REFERENCIAS}

Abarca Rodríguez, A., \& Sánchez Vindas, A. (2005). La deserción estudiantil en la educación superior: el caso de la Universidad de Costa Rica. Revista Electrónica "Actualidades Investigativas En Educación," 5, 1-22. Retrieved from http://www.redalyc.org/pdf/447/44759911.pdf

Abdala Leiva, S., Castiglione, A. M., \& Infante, L. A. (2008). La deserción universitaria. Una asignatura pendiente para la gestión institucional. Cuadernos de La Facultad de Humanidades y Ciencias Sociales. Universidad Nacional de Jujuy, (34), 173-191. Retrieved from http://www.scielo.org.ar/scielo.php?script=sci_arttext\&pid=S166881042008000100012

Alvarez Alvarez, M. B. (2005). Adaptación del método docente al Espacio Europeo de Educación Superior: La motivación de los alumnos como instrumento clave. Estudios Sobre Educación, 9, 107-126. Retrieved from http://web.a.ebscohost.com/ehost/pdfviewer/pdfviewer?vid=1\&sid=89e74a3e-bea6-4d9f8171-103ecd8487dc\%40sdc-v-sessmgr05

Arco Tirado, J. L., Fernández Martín, F. D., \& Fernández Balboa, J. M. (2011). The impact of a peer-tutoring program on quality standards in higher education. Higher Education, 62(6), 773-788. https://doi.org/10.1007/s10734-011-9419-x

Barahona U, P. (2014). Factores determinantes del rendimiento académico de los estudiantes de la Universidad de Atacama. Estudios Pedagógicos (Valdivia), 40(1), 25-39. https://doi.org/10.4067/S0718-07052014000100002

Camarasa, M., Bravo, A., \& García, M. (2014). Cómo cambiar las conductas pasivas en el aula. TESI, 15(3), 56-78. Retrieved from http://revistas.usal.es/index.php/revistatesi/article/view/12218/12563\%0A\%0A

Canales, A., \& De los Ríos, D. (2018). Retención de estudiantes vulnerables en la educación universitaria. Calidad En La Educación, (30), 50-83. https://doi.org/10.31619/caledu.n30.173

Canales, F., Alvarado, E., \& Pineda, E. (1994). Metodología de la Investigación, Manual para el desarrollo de personal de salud (Segunda). Washington, D.C: OPS. Retrieved from http://187.191.86.244/rceis/registro/Metodologia de la Investigacion Manual para el Desarrollo de Personal de Salud.pdf

Dávila Cárdenes, N., García-Artiles, M. D., Pérez-Sánchez, J. M., \& Gómez-Déniz, E. (2015). Un modelo de regresión logística asimétrico que puede explicar la probabilidad de éxito en el rendimiento académico. Revista de Investigación Educativa, 33(1), 27-45. El Higo Revista Científica / Volumen 10. No. 01, pp. 38-52 / Junio 2020 
https://doi.org/10.6018/rie.33.1.178481

Díaz, C. J. (2009). Factores de Deserción Estudiantil en Ingeniería: Una Aplicación de Modelos de Duración. Información Tecnológica, 20(5). https://doi.org/10.4067/S071807642009000500016

García, A. (2014). Rendimiento académico y abandono universitario: Modelos, resultados y alcances de la producción académica en la Argentina. Revista Argentina de Educación Superior, 6(8), 9-38. $\quad$ Retrieved from https://dialnet.unirioja.es/servlet/articulo?codigo $=4753763$

Giovagnoli, P. I. (2002). Determinantes de la deserción y graduación universitaria: Una aplicación utilizando modelos de duración. Universidad Nacional de la Plata. Retrieved from http://www.alfaguia.org/alfaguia/files/1318958623Determinantes de la desercion y graduacion universitaria una aplicacion utilizando modelos de duracion.pdf

Henríquez, N., \& Escobar, D. (2016). Construcción de un modelo de alerta temprana para la detección de estudiantes en riesgo de deserción de la Universidad Metropolitana de Ciencias de la Educación. Revista Mexicana de Investigación Educativa, 21(71), 1221-1248. Retrieved from https://search.proquest.com/docview/1927956258?accountid=168360

Hernández, R., Fernández, C., \& Baptista, P. (2014). Metodología de la Investigación (Sexta). México, D.F.: MacGraw-Hill.

Jansen, E. P. W. A., \& van der Meer, J. (2012). Ready for university? A cross-national study of students' perceived preparedness for university. The Australian Educational Researcher, 39(1), 1-16. https://doi.org/10.1007/s13384-011-0044-6

Jaramillo, S., \& Osses, S. (2012). Validación de un Instrumento sobre Metacognición para Estudiantes de Segundo Ciclo de Educación General Básica. Estudios Pedagógicos (Valdivia), 38(2), 117-131. https://doi.org/10.4067/S0718-07052012000200008

Kohler Herrera, J. (2013). Rendimiento académico, habilidades intelectuales y estrategias de aprendizaje en universitarios de Lima. Liberabit, 19(2), 277-288. Retrieved from https://search.proquest.com/docview/1951022626? accountid=168360

Maslow, A. (1991). Motivación y personalidad. Madrid: Diaz de Santos. Retrieved from https://books.google.es/books?hl=es\&lr=\&id=8wPdj2Jzqg0C\&oi=fnd\&pg=PR13\&dq=polanyi $+\% 2 \mathrm{~B} \% 2 \mathrm{~B}+$ motivacion\&ots=F-

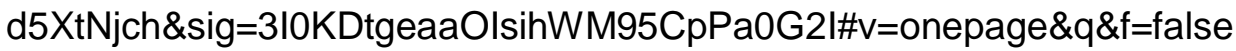

Merlino, A., \& Ayllon, S. (2015). Experiencias en Investigación Educativa. Córdoba, Argentina: Brujas.

Olave Arias, G., Rojas García, I., \& Cisneros Estupiñán, M. (2013). Deserción universitaria y alfabetización académica. Educación y Educadores, 16(3), 455-471. Retrieved from https://search.proquest.com/docview/1503139101?accountid=177584\%0A

Oliveros Ruiz, M. A., Cabrera Córdoba, E., Valdez Salas, B., \& Schorr Wienner, M. (2016). La motivación de las mujeres por las carreras de ingeniería y tecnología. Entreciencias:

El Higo Revista Científica / Volumen 10. No. 01, pp. 38-52 / Junio 2020 
Diálogos En La Sociedad Del Conocimiento, 4(9), 89-96. Retrieved from https://www.redalyc.org/html/4576/457645340007/

Pintrich, P. R., Smith, D., Garcia, T., \& McKeachie, W. (1991). A Manual for the Use of the Motivated Strategies for Learning Questionnaire (MSLQ). Michigan: The University of Michigan. Retrieved from https://files.eric.ed.gov/fulltext/ED338122.pdf

Piura López, J. (2006). Introducción a la Metodología de la Investigación Científica (Nº 1). PAVSA.

Razo Godinez, M. L. (2008). La inserción de las mujeres en las carreras de ingeniería y tecnología. Perfiles Educativos, 30(121), 63-96. Retrieved from http://www.scielo.org.mx/scielo.php?script=sci_arttext\&pid=S018526982008000300004\&lng=es\&tlng=pt.

Romero Ariza, M., \& Pérez Ferra, M. (2009). Cómo motivar a aprender en la universidad: una estrategia fundamental contra el fracaso académico en los nuevos modelos educativos. Revista Iberoamericana de Educación, (51), 87-105.

Salazar Francis, J. P., \& García Solórzano, A. (2011). Estrategias de integración académica para estudiantes de primer ingreso de Ingeniería Agroforestal en URACCAN Bilwi, 2009. Ciencia e Interculturalidad, 7(2), 78. https://doi.org/10.5377/rci.v7i2.440

Tejedor Tejedor, F. J., \& García Valcárcel, A. (2007). Causas del bajo rendimiento del estudiante universitario (en opinión de los profesores y alumnos). Propuestas de mejora en el marco del EEES. Revista de Educación, 342, 443-473. Retrieved from https://www.researchgate.net/publication/28161214

Ugartetxea, J. (2001). Motivación y metacognición, más que una relación. Revista ELectrónica de Investigación y EValuación Educativa, 7(2_1).

Vergara Morales, J. R., Boj del Val, E., Barriga, O. A., \& Díaz Larenas, C. (2017). Factores explicativos de la deserción de estudiantes de pedagogía. Revista Complutense de Educación, 28(2). https://doi.org/10.5209/rev_RCED.2017.v28.n2.50009 


\section{SEMBLANZA DE LOS AUTORES}
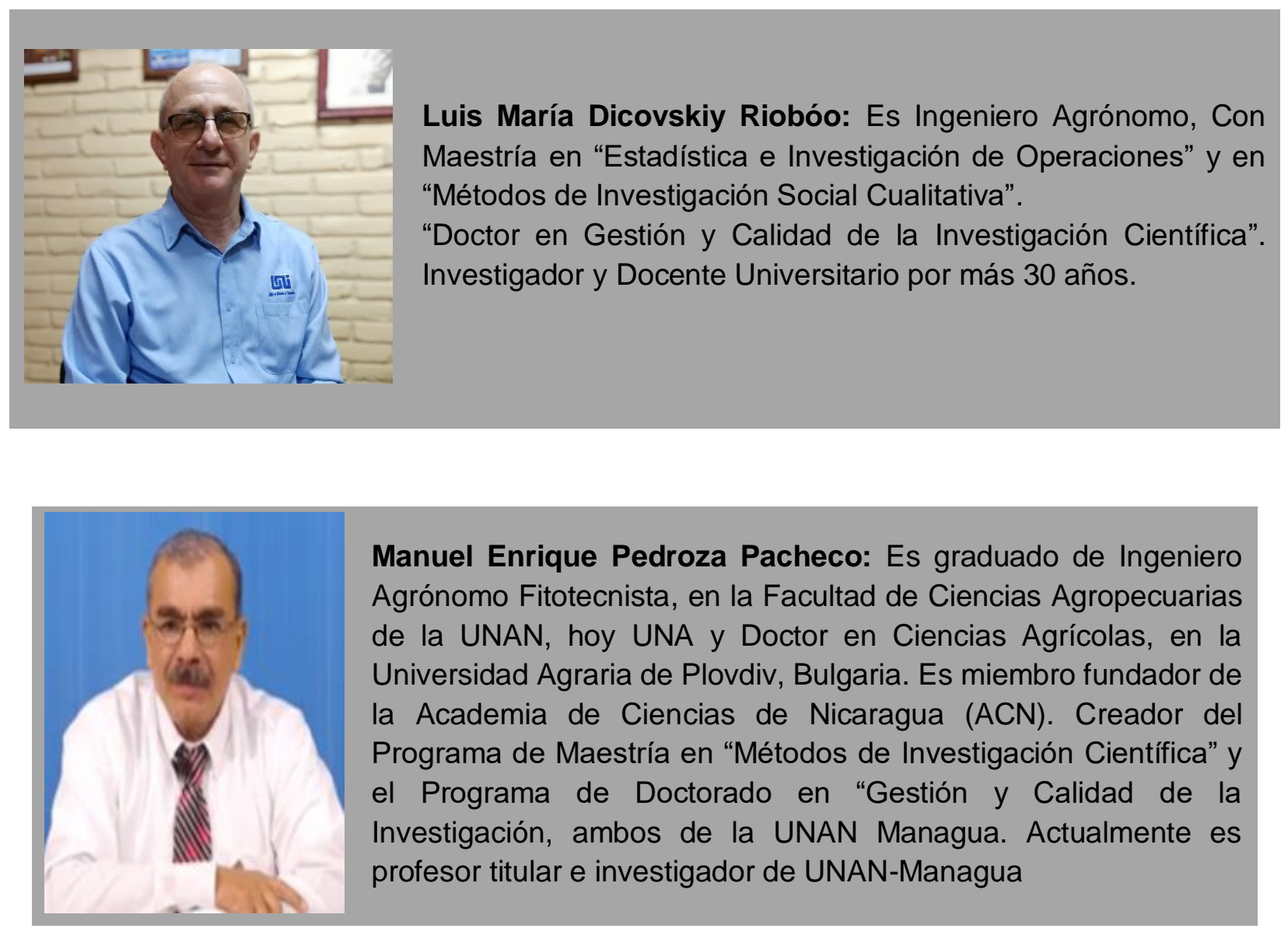

El Higo Revista Científica / Volumen 10. No. 01, pp. 38-52 / Junio 2020 